\title{
Can a policy-induced reduction in alcohol consumption improve health outcomes and stimulate the UK economy?:
}

\author{
A potential "double dividend"
}

Kevin Connolly ${ }^{1}$, Aveek Bhattacharya ${ }^{2}$, Katerina Lisenkova ${ }^{3}$ and Peter G. McGregor ${ }^{4}$

1. Corresponding Author: PhD. Research Assistant. Fraser of Allander Institute and Department of Economics, Sir William Duncan Building, 130 Rottenrow University of Strathclyde, Glasgow, UK, G4 0GE. K.connolly@strath.ac.uk.+441415484553

2. MSc. Policy Analyst. Institute of Alcohol Studies, London, UK

3. PhD. Research Fellow. Fraser of Allander Institute and Department of Economics, University of Strathclyde, Glasgow, UK

4. MSc. Professor (Emeritus). Fraser of Allander Institute and Department of Economics, University of Strathclyde, Glasgow, UK

This is the accepted version of the following article: Connolly, K., et al., (2019). Can a policy-induced reduction in alcohol consumption improve health outcomes and stimulate the UK economy?. Drug and Alcohol Review. 38. Pp 554-560. which has been published in final form at https://onlinelibrary.wiley.com/doi/epdf/10.1111/dar.12962

Word count: Main Text 3406; Abstract 246; Total 3652

Running Headline: Alcohol "double dividend"

Keywords: alcohol consumption in the UK; "gross" and "net" macroeconomic impacts; double dividend; health savings.

Declaration of Interest: None 
Abstract

Introduction and Aims: The health benefits of reducing excessive alcohol consumption are well documented and widely accepted, but policies directed to this end are often regarded as damaging to the economy. Previous UK alcohol impact studies typically focus on what are in effect the "gross" impacts of a fall in alcohol consumption considered in isolation, so that estimated economic impacts are always negative. Here we investigate the "net" impacts of a reduction in consumption accounting for the reallocation of household spending and the expenditure of any increase in government revenues. Design and Methods: We employ a health-augmented, Input-Output modelling framework. We simulate the impact of a reduction in alcohol consumption due to: a change in consumer tastes that generate a reallocation of household spending; an increase in alcohol duties accompanied by the use of increased revenues to stimulate government expenditure. Results: We find evidence of a tradeoff between employment and health benefits for the case of a tastes-induced switch from alcohol consumption, but this is less severe than past analyses would suggest (and does not apply to economic activity more generally). For the case of increased taxation on alcohol (and increased government spending) we find that there is in fact no trade-off between employment on the one hand and health on the other; employment and economic activity are stimulated while health outcomes improve. Conclusion: There is a potential "double-dividend" of improved health outcomes and increased economic activity as a consequence of a rise in alcohol duties. 


\section{Introduction}

The UK has one of the highest alcohol consumption rates per capita in the world being ranked 25th according to the latest global World Health Organisation report on alcohol [1], with binge (excessive) drinking being particularly problematic. While there are several well-documented detrimental effects of excessive alcohol consumption on health, crime and productivity [2], the sector also contributes positively to the economy through its production and sales activities.

Health concerns have prompted governments' efforts in the UK and elsewhere to seek to reduce harmful alcohol consumption, whether through encouraging shifts in public tastes away from such consumption or through the imposition of higher taxes on alcohol [3]. While most would accept that such policies would be likely to have beneficial health effects, there is concern that they would have detrimental effects on the UK economy. For example, previous "impact studies" have produced estimates of the substantial levels of output and employment supported by the UK alcohol industry $[4,5]$.

In this study we explore the likely macroeconomic and health consequences of policy-induced reductions in alcohol consumption using the same basic methodology as impact studies. The two policies we consider here are: a government information campaign that succeeds in shifting consumer tastes away from alcohol; a rise in alcohol taxation. Conventional industry impact studies typically focus on the 'gross' impact of the reduction in consumers' expenditure on alcohol. Gross economic impacts are those generated solely by the reduced spending on alcohol; the assumption is that the income that would have been spent on alcohol is saved. However, a shift in tastes away from alcohol would normally imply a shift in favour of the consumption of other goods and services, and it is the 'net' impact of this switch in consumer spending that governs the overall impact on the economy. Similarly, while a rise in alcohol taxation would be expected to reduce consumption on alcohol, it is likely to augment tax revenues (given a price-inelastic demand for alcohol) and hence allow an increase in government expenditure. Again, the overall impact on the aggregate economy depends upon the 'net' effect of the reduction in alcohol consumption and increase in public spending.

Of course, we know that the 'gross' macroeconomic impact of a reduction in the consumption of alcohol must be negative: the reduction in demand reduces economic activity. If policy inappropriately focuses exclusively on the 'gross' impacts there would appear to be an unavoidable trade-off between the adverse economic consequences of a reduction in consumption and any beneficial health or wider social effects. However, the appropriate focus for policy is the net effect that drives the economic impact. Since this effect is the outcome of conflicting pressures even the direction of the 'net' 
macroeconomic outcome is unknown a priori; it becomes an empirical issue. Furthermore, a policy aimed at shifting tastes or changing taxes to reduce alcohol consumption could yield a "double dividend" of a positive (net) economic impact as well as improved health outcomes. The idea of a policy "double dividend" was introduced in the literature on environmental policy to describe circumstances in which a carbon tax simultaneously improves the economy and reduces carbon emissions( e.g. [6]). This paper explores the direction and scale of likely gross and net economic impacts as well as the beneficial health effects of a policy-induced reduction in alcohol consumption in the UK.

The paper is organised as follows. Section 2 provides a literature review. Section 3 details the methodology adopted and the scenarios that are modelled. Section 4 discusses the results and Section 5 concludes.

The health and economic impacts of alcohol

One common objection to measures to reduce harmful drinking is that they lead to lower consumer spending on alcohol, which in turn will have a negative effect on the economy. Several studies have sought to highlight the economic contribution of alcohol production and sales in the UK and other countries. These typically take the form of conventional 'impact studies', which seek to determine the level of output and employment supported by the alcohol industry [4][5][7].

While these impact studies reflect a conventional use of input-output (IO) modelling, they can be misleading if considered in isolation. For instance, the Wine and Spirit Trade Association (WTSA) used EY's [7] analysis to call for the abolition of the alcohol duty escalator, claiming that it demonstrated that the tax was "bad for the economy, and bad for business". The British Beer and Pub Association argued, on the basis of Oxford Economics' [4] analysis, that cuts to beer duty between 2013 and 2015 had "brought huge benefits, created jobs and encouraged investment".

These claims can be misleading because the research they cite considers only the gross impact of changes in alcohol spending on the economy. However, as already noted, reductions in harmful alcohol consumption - whether induced by changes in tastes or by taxation - are likely to lead to increases in the consumption of other goods, and it is the 'net' impact of a change in spending that matters. Very few studies have studied the 'net' impact of a change in alcohol spending.

One exception is Wada et al [8], who use a dynamic model integrating $\mathrm{IO}$ and computable general equilibrium methods to model the impact of a change in alcohol policy. They find that an increase in alcohol excise taxes, with the revenue re-allocated to general government expenditure, creates a net increase in employment. 
A vast number of studies have also documented the negative health consequences of harmful alcohol consumption $[9,10]$ including an increased risk of several types of cancer; cardiovascular disease; liver disease, high blood pressure; dementia and depression.

Harmful drinking also carries a cost to the wider society, beyond the drinker [11]. Alcohol-related illness increases health care costs, for which society pays through higher taxes [12]. Purshouse et al [13] analyse the potential health cost savings resulting from policy changes focused on reducing alcohol consumption in England and we use their estimates to evaluate the health impact of changes in alcohol consumption in our own analysis.

Various studies have explored the link between alcohol consumption and a range of individual economic outcomes, including: wages [14,15]; unemployment [16,17]; absence due to sickness $[18,19]$ and performance at work [20]. In general, this research finds that heavy drinking has negative economic consequences, though the evidence is more ambiguous in the case of wages [21]. Premature deaths due to alcohol also have the effect of reducing the labour force [22].

\section{Methods}

\section{Modelling macroeconomic and health outcomes}

To evaluate the macroeconomic consequences of changes in alcohol consumption we adopt the same modelling approach (IO) as previous "impact studies" of the UK alcohol sector [4,5,7], although we apply it to determine the net economic impacts of a reduction in alcohol consumption. To our knowledge this is the first study of the UK that identifies the importance of net macroeconomic effects and seeks to identify their direction and scale. Additionally, the present paper also identifies the likely reduction in health service costs associated with a reduction in alcohol consumption and so allows us to establish whether there is in fact a genuine trade-off between health and economic outcomes, or whether there is potential for a "double dividend".

IO tables are a set of economic accounts, which provide a complete picture of an economy over a year. Generated through the use of surveys and other data, 10 tables contain information on the value of inter-industrial (based on SIC classification) transactions in the economy. In these tables the rows represent the sectoral sales, while the columns represent their purchases. As well as intermediate sales and purchases to other sectors, these tables contain information on sales to exports and expenditure on imports, wages, taxes etc. A key feature of these 10 tables is that they must balance, i.e. the total sales of a sector equals its total purchases. 
An 10 model can be calibrated on the IO database. This captures the linkages between each sector within the economy using a set of linear equations. The system can be solved to determine the economic impact of any exogenous demand shock, given certain assumptions about the nature of the economy, in particular, the passive nature of supply. In our case the fall in alcohol consumption, for example, reduces demand for the outputs of those sectors supplying alcohol to consumers. However, this impacts the other sectors that sell intermediate inputs to the alcohol sectors, which in turn has knock-on effects to yet more sectors. As a result the initial change in consumption is subject to a "multiplier" effect on value-added, output and employment. IO models capture three types of effectsdirect, indirect and induced. Direct effects relate simply to changes in the 'shocked' sector; indirect effects reflect sectors' intermediate purchases and the supply chain, and induced effects refer to the impacts on consumption due to changes in employment (and labour income, i.e a change in employment increases household disposable income, stimulating spending on other goods and services).

The present analysis uses an 10 model calibrated to a purpose-built 106 sector 2010 UK alcoholdisaggregated IO table. Within the alcohol industry we identify two key components, production and consumption. In this paper, as the focus is solely on the economic and health impacts of consumption changes, we extend the 10 table by disaggregating the alcohol sales of three sectors - hotels, other on-trade (including pubs/bars/restaurants/nightclubs etc.) and retail (off-trade). A description of how this IO table is constructed is provided in Appendix I and the structure of the corresponding IO model is summarised in Appendix II. The augmented IO table is publicly available [23].

Improvements in health outcomes are estimated as the health service cost savings that result from the reduction in alcohol consumption. Purshouse et al [13] consider the health savings from a range of policy scenarios, which we use to estimate a simple health cost multiplier associated with changes in alcohol consumption. These provide an estimated average cost to the NHS (in 2018 prices) of each unit of alcohol consumed, which is used to assess the likely overall cost savings from any reduction in alcohol consumption. (See equation 9 of Appendix II).

\section{Scenarios}

While the UK Government's alcohol strategy seeks a reduction of harmful alcohol consumption [3], it does not specify any numerical target. However, the World Health Organisation (WHO) recommends an overall $10 \%$ reduction in alcohol consumption to reduce negative health effects [24]. Accordingly, we here explore both the macroeconomic and health saving impact of a $10 \%$ reduction in UK alcohol consumption, which we take to reflect a successful Government information/ persuasion campaign to 
induce a switch in tastes away from alcohol. The simulation assumes that there is a $10 \%$ reduction in consumption across all alcohol types (beer, spirits etc) and across all three disaggregated IO alcohol sectors (with the price of alcohol fixed).

While we follow the various impact studies discussed in Section 2 in estimating the gross macroeconomic impacts of the $10 \%$ reduction in alcohol consumption we also provide estimates of the net effects. Here we assume that the income saved by the $10 \%$ reduction in alcohol consumption is spent on the outputs of the other sectors of the economy based on the pattern of household spending within the IO tables (Appendix II details the methodology used in the paper).

Whether Government health messages do in fact succeed in inducing changes in tastes is uncertain; rather more certain is that tax rises are likely to have a significant effect due to the price-sensitivity of alcohol demand $A$ price increase due to a tax rise will reduce alcohol consumption. The UK alcohol strategy [3] identified the low price of alcohol as problematic, since the low price drives higher consumption [25], which can, as already noted, lead to various adverse health effects. The simplest method to reduce consumption is to increase the price through a tax. There is no 'one size fits all' alcohol tax in the UK. Instead the tax levied is dependent on the type of alcohol. In this scenario we assume a $10 \%$ increase in the tax duty on all types of alcohol across the three consumption sectors.

The consumption response to a change in price for each type of alcohol (and for both the on-trade and off-trade) is based on the own-price elasticities in Meng at al [25]. Most reported elasticities are between 0 and -1 indicating that as the price rises demand falls, but less than in proportion to the fall in price, so that total expenditure on alcohol increases. Accordingly, Government revenues actually increase in response to a tax rise.

We report both the 'gross' and 'net' impacts of a $10 \%$ increase in UK tax rates. The former case focusses exclusively on the tax-induced reduction in alcohol consumption, whereas the net estimate also takes account of the increase in Government expenditure that the stimulus to tax revenues allows. The literature has many examples of 10 analysis of switching expenditures, including [26, 27 and 28].

\section{Results}


We first consider the impact of a successful government campaign that succeeds in securing a shift in tastes, so that alcohol consumption falls by ' $10 \%$. Overall 'gross' economic impacts are, of course, always negative, since these assume (often implicitly) that income that is no longer spent on alcohol is saved. Once the reallocation of spending is included, however, the estimated 'net' impacts are very different from their gross counterparts

Table 1. Headline results for simulations



*Note: GVA is Gross Value Added

*Note: FTE is Full Time Equivalent employment

Figure 1 gives 'net' GVA increases across the 11 sectors of the economy that register the greatest increase with a $10 \%$ reduction in alcohol sales (we focus on the 10 sectors that register the greatest impacts, with the $11^{\text {th }}$ sector 'other' being an aggregation of the rest of the economy).

\footnotetext{
${ }^{1}$ Direct output is the $\Delta \mathrm{f}$ introduced into the model
} 
Office Administrative, Office Support And Other Business... Employment Activities

\section{Education}

Food And Beverage Service Activities (non-Alcohol) Manufacture of bakery and farinaceous products Wholesale And Retail Trade And Repair Of Motor Vehicles...

\section{Construction}

Land transport services and transport services via pipelines,...

Warehousing And Support Activities For Transportation Real estate activities on a fee or contract basis

Buying and selling, renting and operating of own or leased...

$$
\begin{array}{cccccccc}
0 & 10 & 20 & 30 & 40 & 50 & 60 & 70 \\
\text { GVA } & \text { Increase (fmillion) }
\end{array}
$$

* Note: GVA is Gross Value Added

Figure 2 shows the effects on the eight most impacted sectors (again we only focus on these sectors as they have the largest 'net' impact) with a $10 \%$ increase in alcohol duty.

Figure 2 'Gross' and 'net' employment changes across 8 sectors with $10 \%$ increase in alcohol duty

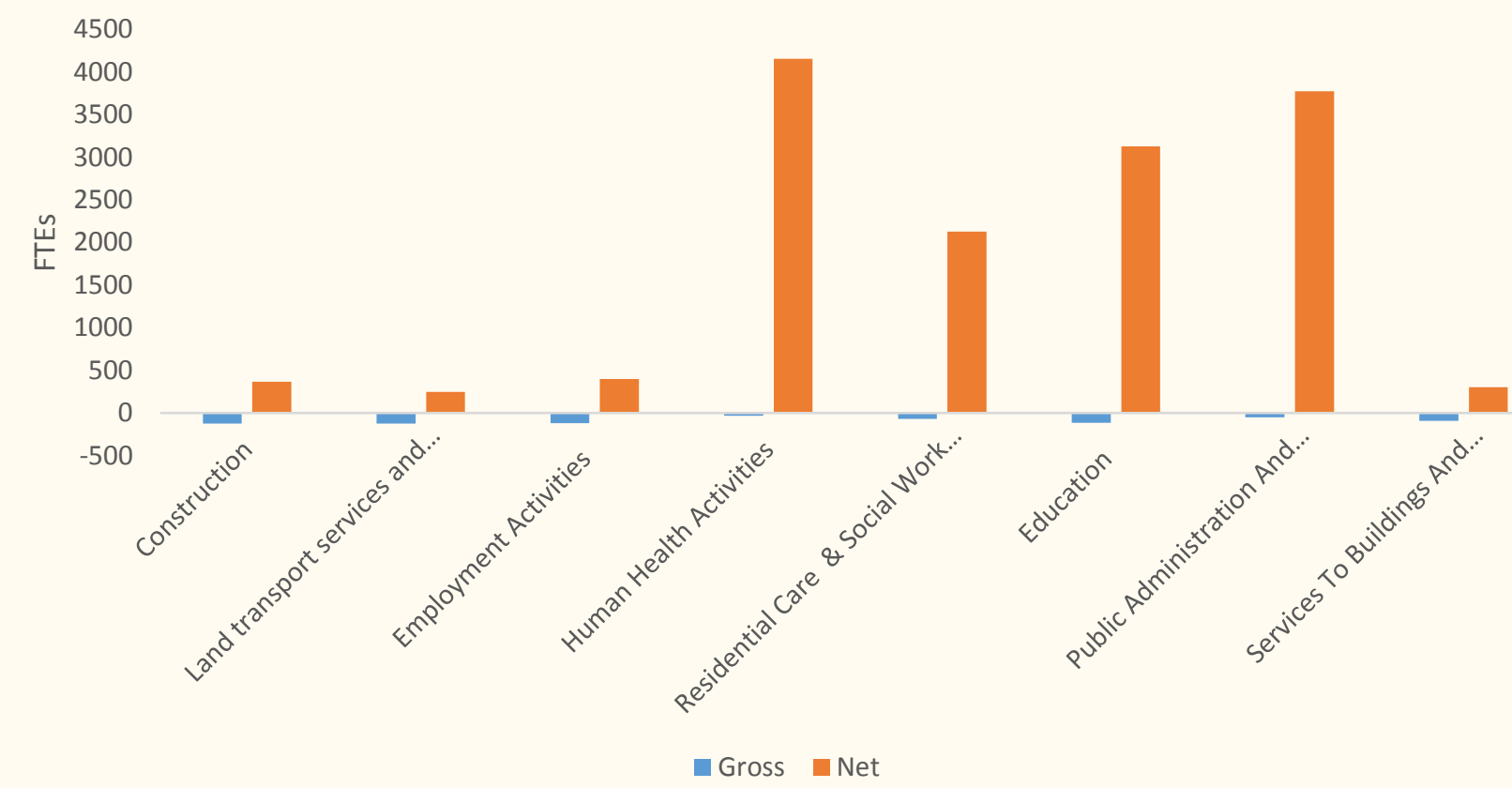

*Note: FTE is Full time Equivalent employment

\section{Discussion}

'Gross' and 'net' impacts of a 10\% Reduction in alcohol consumption 
Headline results for a $10 \%$ decrease in alcohol consumption are summarised in Table 1 . Here there is a f2. 6 billion reduction in Gross Value Added (GVA), employment drops by 63,000 full-time-equivalent employees (FTEs) along with a reduction in Government revenue from VAT and alcohol duty amounting to $f 1.34$ billion. These results are in line with those reported in $[[4,5,7$ and 8$]$.

Overall, with 'net' impacts, there is no change in initial total spending in the economy (as savings from reduced alcohol consumption are all spent on other sectors' outputs), but there is still a loss in employment. However, this is significantly reduced compared to the gross estimate $(21,700$ rather than 63,300 FTEs). Furthermore, there is actually a small increase in GVA of $£ 23$ million. The alcohol sales sectors are, on average when compared with the rest of the economy, comparatively labour intensive, but not GVA intensive.

A $10 \%$ reduction in alcohol consumption has a significant impact on the costs incurred by the health services. Using the cost of a unit of alcohol calculated as indicated above we estimate that a $10 \%$ reduction in alcohol consumption could save the NHS $f 787.5$ million. The shift in tastes away from alcohol results in substantial savings for the NHS and a small stimulus to GVA, but employment falls. While there is the possibility of a modest "double dividend" for GVA, there appears to be a trade-off between health and employment effects (reflecting the labour intensity of alcohol relative to general spending).

\section{Impacts of a $10 \%$ Increase in Alcohol duty}

Since alcohol duty constitutes only a part of the total price of alcohol, the $10 \%$ increase in tax results in a less than proportionate increase in consumer prices. The changes in price and induced reductions in alcohol consumption (using price elasticities of demand [25]) are detailed in Appendix II (equations 11 through 15). The gross impact, reported in the lower half of Table 1, implies a reduction of $£ 294$ million GVA and a loss of 7,300 FTE jobs.

The increase in tax also impacts government revenues, however, with an overall net positive impact of $£ 788.7$ million. A $10 \%$ increase in tax results in an increase in government revenue through


generates a net fall in VAT revenue of $£ 46.7$ million (assuming the standard VAT rate and accounting for the change in VAT on alcohol duty).

The 'net' impact of the tax rise is obtained by using the $f 788.7$ million net increase in tax revenues to increase public spending (in line with the allocation of government expenditure in the original UK IO 
table). In this case there is a positive impact on employment of 17,000 FTE jobs and GVA of $£ 847$ million. From Figure 2, a large share (77.3\%) of the overall employment change occurs in just four sectors. Of the 17,041 increase in FTEs: 3772 occur in public administration; 3128 in education; 4153 in health and 2127 in residential care and social work, the (labour-intensive) sectors that are most closely linked to public expenditure.

Note that revenue reallocation here already implies a direct benefit to health services, even before considering the savings to the NHS of a reduction in alcohol consumption.

The introduction of a higher tax rate generates a reduction in consumption, which impacts the health services. We estimate that the $10 \%$ rise in alcohol duty could lead to a saving of $£ 123.3$ million in health costs. While this is a much lower saving than is implied by the $10 \%$ reduction in consumption, here the unambiguously positive economic impacts imply the presence of a "double dividend" for the UK.

\section{Conclusions}

Health concerns have prompted recent UK Government efforts to seek to reduce harmful alcohol consumption, whether through attempts to shift public tastes away from such consumption or through the imposition of higher taxes on alcohol. While there is little controversy that policies directed towards reducing alcohol consumption would improve health outcomes, there is concern that they might impact negatively on the economy.

While any reduction in alcohol consumption would, in itself, have an adverse impact on the economy this is only part of the overall effect of either a shift in tastes due to a persuasive information campaign or higher alcohol duties. In the case of a shift in tastes, consumption of other goods and services is likely to increase, and the overall impact on the economy depends on the 'net' impact of this switch in spending. Similarly, while a rise in alcohol duties reduces consumption of alcohol, any rise in tax revenues allows an increase in public spending and the 'net' impact on the economy depends on the outcome of these countervailing forces.

Our results confirm that a reduction in consumption of alcohol alone, without considering the likely reallocation of consumption spending in the case of a shift in tastes or the reallocation of the increase tax revenues in the case of an increase in duties, has significant negative effects on the UK economy. This broadly captures the approach of conventional alcohol industry "impact studies". In this "gross impact' view, there would appear to be an unavoidable trade-off between the health benefits of policies aimed at reducing alcohol consumption and an adverse impact on the economy. However, in 
fact it is the 'net' impact that matters for the macroeconomic consequences of a reduction in alcohol consumption. When proper account is taken of the reallocation of expenditures in the case of a shift in tastes away from alcohol consumption and towards other goods and services we find that for employment the trade-off is significantly relaxed, and is entirely absent for value-added. In the case of an increase in alcohol duties we find evidence of a net positive effect on both value-added and employment in addition to improved health outcomes, indicating that here there is no trade-off: indeed there is potential for a "double dividend" of a simultaneous improvement in health and a stimulus to the UK economy.

Future research should extend the system-wide analysis to encompass an alcohol-disaggregated computable general equilibrium model of the UK, which would relax the passive supply assumption of input-output and allow explicit analysis the supply-side impacts of a fall in alcohol consumption such as the stimulus to productivity associated with reduced absenteeism and presenteeism. In [28], for example, we develop a micro-to-macro analysis of the impact of higher education institutions' graduates' enhanced productivity on their host region's economies.

Such an analysis is likely to reveal higher level "dividends",or "multiple benefits", [29], of policies directed at moderating harmful alcohol consumption. 


\section{Acknowledgements}

This study is based on independent research carried out in the Fraser of Allander Institute, funded by the Institute for Alcohol Studies (IAS). We are indebted to two anonymous referees and an editor for very helpful comments on an earlier draft.

\section{References}

[1] World Health Organisation. (2014). Global status report on alcohol and health 2014. Global status report on alcohol.

https://apps.who.int/iris/bitstream/handle/10665/112736/9789240692763 eng.pdf;jsessionid=9FC 786C546C67A2E0E5E2DBAC3A4DC7D? sequence=1. Accessed 20/05/19

[2] Holmes, J., Angus, C., Buykx, P., Ally, A., Stone, T., Meier, P., \& Brennan, A. (2016). Mortality and morbidity risks from alcohol consumption in the UK: Analyses using the Sheffield Alcohol Policy Model (v.2.7) to inform the UK Chief Medical Officers' review of the UK lower risk drinking guidelines Final report. Retrieved from

https://www.sheffield.ac.uk/polopoly fs/1.538671!/file/Drinking Guidelines Final Report Publishe d.pdf. Accessed 20/05/19

[3] UK Government. (2012). The Government 's Alcohol Strategy The Government ' s Alcohol Strategy. Retrieved from https://www.gov.uk/government/publications/alcohol-strategy. Accessed 20/05/19

[4] Oxford Economics. (2016). The local impact of the UK beet and pub sector. A Report for the British Beer and Pub Association (BBPA).. Retrieved from https://s3.amazonaws.com/bbpaprod/attachments/documents/uploads/24436/original/BBPA\%202016\%20UK\%20report.pdf?148404 5624. Accessed 20/05/19

[5] Berkhout, B., Berting, L., Bleeker, Y., de Wit, W., Kruis, G., Stokkel, R., \& Theuws, R. (2013). The Contribution made by Beer to the European Economy. Retrieved from https://www.brewersofeurope.org/uploads/mycmsfiles/documents/archives/publications/2013/FullReport20140123.pdf. Accessed 20/05/19

[6] Goulder, L. H. (1995) Environmental taxation and the double dividend: A reader's guide. International Tax and Public Finance, 2(2), 157-183.

[7] EY. (2013). The Wine and Spirit Trade Association Economic impact assessment. Retrieved from http://www.wsta.co.uk/images/budget/EY-final-ADE-report-for-WSTA.pdf. Accessed 20/05/19

[8] Wada, R., Chaloupka, F. J., Powell, L. M., \& Jernigan, D. H. (2017). Employment impacts of alcohol taxes. Preventive Medicine, 105(August), S50-S55. https://doi.org/10.1016/j.ypmed.2017.08.013

[9] Corrao, G., Bagnardi, V., Zambon, A., \& La Vecchia, C. (2004). A meta-analysis of alcohol consumption and the risk of 15 diseases. Preventive Medicine, 38(5), 613-619. https://doi.org/10.1016/j.ypmed.2003.11.027 
[10] Ridolfo and Stevenson. (2001). The quantification of drug-caused mortality and morbidity in Australia. Drug Statistics Series, 7, 1-147. Retrieved from http://www.aihw.gov.au/publications/phe/qdcmma98/qdcmma98.pdf

[11] Jarl, J., Johansson, P., Eriksson, A., Eriksson, M., Gerdtham, U. G., Hemström, Ö., ... Room, R. (2008). The societal cost of alcohol consumption: An estimation of the economic and human cost including health effects in Sweden, 2002. European Journal of Health Economics, 9(4), 351-360. https://doi.org/10.1007/s10198-007-0082-1

[12] Leicester, A. (2011). Alcohol pricing and taxation policies. IFS Briefing Note, BN124, 40. Retrieved from https://www.ifs.org.uk/bns/bn124.pdf. Accessed 20/05/19

[13] Purshouse, R. C., Meier, P. S., Brennan, A., Taylor, K. B., \& Rafia, R. (2010). Estimated effect of alcohol pricing policies on health and health economic outcomes in England: an epidemiological model. The Lancet, 375(9723), 1355-1364. https://doi.org/10.1016/S0140-6736(10)60058-X

[14] Peters, B. L. (2004). Is there a wage bonus from drinking? Unobserved heterogeneity examined. Applied Economics, 36(20), 2299-2315. https://doi.org/10.1080/0003684042000280526

[15] Macdonald, Z., \& Shields, M. (2001). The Impact of Alcohol Use on Occupational Attainment and Wages $\not$, 68(271), 427-453.

[16] MacDonald, Z., \& Shields, M. A. (2004). Does problem drinking affect employment? Evidence from England. Health Economics, 13(2), 139-155. https://doi.org/10.1002/hec.816

[17] Henkel, D. (2011). Unemployment and substance use: a review of the literature (1990-2010). Current Drug Abuse Reviews, 4(1), 4-27. https://doi.org/10.2174/1874473711104010004

[18] Norström, T. (2006). Per capita alcohol consumption and sickness absence. Addiction, 101(10), 1421-1427. https://doi.org/10.1111/j.1360-0443.2006.01446.x

[19] Roche, A. M., Pidd, K., Berry, J. G., \& Harrison, J. E. (2008). Workers' drinking patterns: The impact on absenteeism in the Australian work-place. Addiction, 103(5), 738-748.

https://doi.org/10.1111/j.1360-0443.2008.02154.x

[20] Holden, L., Scuffham, P. A., Hilton, M. F., Ware, R. S., Vecchio, N., \& Whiteford, H. A. (2011). Health-related productivity losses increase when the health condition is co-morbid with psychological distress: Findings from a large cross-sectional sample of working Australians. BMC Public Health, 11: 1-9 https://doi.org/10.1186/1471-2458-11-417

[21] IAS. (2017). Splitting the bill: Alcohol's impact on the economy Retrieved from http://www.ias.org.uk/uploads/pdf/Socioeconomic groups/Socioeconomic groups and alcohol factsheet February 2014.pdf. Accessed 20/05/19

[22] Public Health England. (2016). The Public Health Burden of Alcohol and the Effectiveness and Cost-Effectiveness of Alcohol Control Policies An evidence review. https://doi.org/10.1016/S0140$\underline{6736(16) 32420-5}$

[23] Connolly, K. (2019). 2010 UK alcohol consumption disaggregated IxI table. https://doi.org/10.15129/cfb2d861-2856-437b-bd45-ed37dbee9900

[24] World Health Organisation. (2014). Reduce harmful use of alcohol. Retrieved from http://www.who.int/nmh/ncd-tools/target2/en/. 
[25] Meng, Y., Brennan, A., Purshouse, R., Hill-McManus, D., Angus, C., Holmes, J., \& Meier, P. S. (2014). Estimation of own and cross price elasticities of alcohol demand in the UK-A pseudo-panel approach using the Living Costs and Food Survey 2001-2009. Journal of Health Economics, 34(1), 96103. https://doi.org/10.1016/i.jhealeco.2013.12.006

[26] Allan, G., Dunlop, S., \& Swales, K. (2007). The economic impact of regular season sporting competitions: the Glasgow Old Firm football spectators as sports tourists. Journal of Sport Tourism, 12(2), 63-97.

[27] Hermannsson, K., Lisenkova, K., McGregor, P. G., \& Swales, J. K. (2014). 'Policy scepticism' and the impact of Scottish higher education institutions (HEIs) on their host region: Accounting for regional budget constraints under devolution. Regional Studies, 48(2), 400-417.

[28] Hermannsson, K., McGregor, P. G., \& Swales, J. K. (2018). Students' consumption expenditures in economic impact studies: assumptions revisited in an input-output approach for Scotland.

Regional Studies, Regional Science, 5(1), 57-77.

[29] IEA (2014). Capturing the Multiple Benefits of Energy Efficiency: A Guide to Quantifying the Value Aded. IEA, Paris. 